\title{
MÉTODOS DE EXTRAÇÃO E/OU CONCENTRAÇÃO DE COMPOSTOS ENCONTRADOS EM FLUIDOS BIOLÓGICOS PARA POSTERIOR DETERMINAÇÃO CROMATOGRÁFICA
}

\author{
Sonia C. N. Queiroz, Carol H. Collins e Isabel C. S. F. Jardim \\ Instituto de Química, Universidade Estadual de Campinas, CP 6154, 13083-970 Campinas - SP
}

Recebido em 13/12/99; aceito em 25/10/00

\begin{abstract}
METHODS OF EXTRACTION AND/OR CONCENTRATION OF COMPOUNDS FOUND IN BIOLOGICAL FLUIDS FOR SUBSEQUENT CHROMATOGRAPHIC DETERMINATION. When organic compounds present in biological fluids are analysed by chromatographic methods, it is generally necessary to carry out a prior sample preparation due the high complexity of this type of sample, especially when the compounds to be determinated are found in very low concentrations. This article describes some of the principal methods for sample preparation in analyses of substances present in biological fluids. The methods include liquid-liquid extraction, solid phase extraction, supercritical fluid extraction and extraction using solid and liquid membranes. The advantages and disadvantages of these methods are discussed.
\end{abstract}

Keywords: sample preparation; biological fluids; extraction methods.

\section{INTRODUÇÃO}

As áreas que têm interesse em análises de compostos encontrados em fluidos biológicos são muitas: ambiental, farmacêutica, análises clínicas, medicina legal, etc ${ }^{1-3}$. A análise cromatográfica de substâncias presentes nestes tipos de matrizes (soro, plasma, urina, etc), em geral, requer um pré-tratamento da amostra. As razões para isso são inúmeras, destacando-se a complexidade das matrizes biológicas, das quais os compostos são obtidos, a existência de proteínas que são incompatíveis com as colunas cromatográficas ${ }^{3}$ e a concentração das substâncias a serem analisadas, a nível de traço. As técnicas de extração e/ou pré-concentração permitem que a análise dos componentes de interesse se torne possível. A meta final é a obtenção de uma sub-fração da amostra original enriquecida com as substâncias de interesse analítico, de forma que se obtenha uma separação cromatográfica livre de interferentes, com detecção adequada e um tempo razoável de análise.

As técnicas mais comumente utilizadas para extração e/ou pré-concentração de compostos presentes em fluidos biológicos são: extração líquido-líquido, extração em fase sólida, extração com fluido supercrítico e extração com membranas sólidas (diálise e ultrafiltração) ou líquidas. Estas técnicas de preparação de amostras têm sido automatizadas para uso em análises de rotina, pois eliminam erros humanos de manipulação, diminuem o tempo de assistência do analista durante a análise, evitam o risco de contato com substâncias prejudiciais à saúde e aumentam, significativamente, o número de análises de amostras por tempo. Estas técnicas podem ser subdivididas em dois modos: "off-line" e "on-line" 4 . No "off-line", a etapa de extração e/ou concentração do analito é realizada separadamente do sistema cromatográfico. Após o preparo, a amostra é introduzida no sistema cromatográfico por meio de um injetor, como qualquer outra amostra. Hoje em dia, muitos equipamentos para extrações múltiplas são disponíveis comercialmente. Alguns deles fazem o processo de extração automaticamente, mas a transferência da amostra para o injetor cromatográfico é manual (sistema semi-automático), enquanto outros, além de extração automatizada, são também capazes de transferir a

e-mails: soniacnq@iqm.unicamp.br; chc@iqm.unicamp.br; icsfj@iqm.unicamp.br amostra ao sistema cromatográfico (sistema completamente automático). No sistema "on-line", a etapa de extração e/ou concentração do analito é realizada no próprio sistema cromatográfico, onde são inseridos alguns acessórios.

Existem muitas publicações especializadas descrevendo os processos de preparação de amostras para análise de analitos individuais ou classes de compostos, de forma que descrever todos eles seria impossível. Dessa maneira, neste artigo serão discutidos os métodos de extração e/ou pré-concentração mais utilizados em análises de compostos presentes em fluidos biológicos, as suas características e aplicações.

\section{EXTRAÇÃO LÍQUIDO-LÍQUIDO (ELL)}

$\mathrm{Na}$ extração líquido-líquido ocorre a partição da amostra entre duas fases imiscíveis (orgânica e aquosa). A eficiência da extração depende da afinidade do soluto pelo solvente de extração, da razão das fases e do número de extrações. Para alguns sistemas, o valor da constante de distribuição, $K_{D}$, entre as fases pode ser aumentado pelo ajuste do $\mathrm{pH}$, para prevenir a ionização de ácidos ou bases, pela formação de par iônico com solutos ionizáveis, pela formação de complexos lipofílicos com íons metálicos ou pela adição de sais neutros, para diminuir a solubilidade de compostos orgânicos na fase aquosa ${ }^{5}$.

A ELL apresenta as vantagens de ser simples (na configuração mais comum usa-se um funil de separação ou tubos de centrífuga) e poder utilizar um número grande de solventes, puros e disponíveis comercialmente, os quais fornecem uma ampla faixa de solubilidade e seletividade. Além disso, as proteínas presentes nas amostras são denaturadas, eliminando a contaminação da coluna cromatográfica. Por outro lado, esta técnica possui uma série de desvantagens, tais como: as amostras com alta afinidade pela água são parcialmente extraídas pelo solvente orgânico, resultando em perda do analito; impurezas do solvente são concentradas junto com a amostra, implicando no uso de solventes ultrapuros; pode ocorrer a formação de emulsões, o que resulta em grande consumo de tempo; volumes relativamente grandes de amostras e de solventes são requeridos, gerando problemas de descartes; alguns solventes orgânicos são tóxicos; pode ocorrer adsorção dos analitos na vidraria; decomposição de compostos instáveis termicamente, na etapa de pré-concentração; o processo é suscetível a erros e, relativamente, de difícil automação. Apesar destas desvantagens, 
a ELL é considerada uma técnica clássica de preparação de amostra e tem sido ainda muito utilizada em análises de diversos tipos de substâncias presentes em fluidos biológicos, pois extratos bastante limpos podem ser obtidos com alta seletividade para alguns analitos.

\section{Aplicações de ELL em fluidos biológicos}

A escolha adequada do solvente orgânico e o ajuste de $\mathrm{pH}$ da amostra são necessários para assegurar uma boa recuperação do analito. A extração de substâncias básicas é, normalmente, realizada a $\mathrm{pH}$ maiores que 7 e a extração de substâncias ácidas é feita em $\mathrm{pH}$ menores que 5. Vários tipos de solventes orgânicos têm sido empregados na extração de drogas ácidas e básicas presentes em amostras de fluidos biológicos, tais como, éter dietílico ${ }^{6-10}$, acetato de etila ${ }^{11-13}$, hexano 14 , tolueno ${ }^{15,16}$, diclorometano ${ }^{17-19}$, acetato de butila ${ }^{20}$, misturas de solventes ${ }^{21-24}$, etc. Quanto maior a afinidade do analito pelo solvente orgânico maior a recuperação.

Yoshida e Akane ${ }^{25}$ descreveram, recentemente, a extração de benzodiazepínicos em soro, por meio de um método de extração novo denominado "extração líquido-líquido à temperatura sub-zero". Os autores utilizaram acetonitrila a $-20^{\circ} \mathrm{C}$ como solvente de extração, pois nesta temperatura há uma separação entre as fases. Após a extração, a fase contendo acetonitrila foi injetada diretamente no sistema cromatográfico e boa reprodutibilidade entre as extrações foi obtida.

A ELL foi empregada para a determinação de 25 pesticidas organofosforados, em soro humano, por meio de extração com $n$-hexano/acetato de etila $(75: 25, \mathrm{v} / \mathrm{v})$ seguida por cromatografia em camada delgada de alta eficiência. Neste método utilizaram-se $1 \mathrm{~mL}$ de amostra, $1 \mathrm{~mL}$ de solvente orgânico e $1 \mathrm{~mL}$ de solução aquosa de cloreto de sódio saturada, sendo que o sal foi empregado para diminuir a solubilidade do analito na fase aquosa e também para evitar a formação de emulsões. Os limites de detecção foram suficientemente baixos para detectar os pesticidas em pacientes intoxicados ${ }^{26}$.

Uma metodologia para análise de bifenilas policloradas (PCB) em soro usando ELL para subseqüente análise por cromatografia gasosa, com detector espectrométrico de massas, foi descrita por Pauwels e Schepens ${ }^{27}$. Após a ELL foi feita uma etapa de remoção dos interferentes através da percolação do extrato através de uma coluna de adsorção de sílica gel desativada. O sistema de solventes consistiu de $30 \mathrm{~mL}$ de $\mathrm{n}$ hexano, seguido de $10 \mathrm{~mL}$ de $\mathrm{n}$-hexano:diclorometano (80:20, $\mathrm{v} / \mathrm{v})$ e $10 \mathrm{~mL}$ de $\mathrm{n}$-hexano:diclorometano (40:60, v/v).

Marques et $a l^{28}$ publicaram uma metodologia para análise de estriquinina, que é um alcalóide altamente tóxico para os seres humanos. Os autores empregaram uma mistura de tolueno/n-heptano/álcool isoamílico $(67: 20: 4$, v/v/v) para extrair a substância tóxica de amostras biológicas, para fins de investigações clínicas e forense, com determinação por cromatografia gasosa acoplada à espectrometria de massas.

Outros exemplos representativos da ELL em amostras biológicas incluem a extração de fármacos de leite materno ${ }^{29,} 30 \mathrm{e}$ em fluido cérebro-espinhal ${ }^{31}$.

\section{Automação}

Atualmente, com o surgimento de técnicas modernas de separação, tal como a cromatografia líquida de alta eficiência acoplada à espectrometria de massas (CL/EM ou CL/EM/EM), análises muito rápidas podem ser realizadas devido à alta seletividade alcançada pelo detector (EM) quando se utiliza o modo "SIM" (Monitoramento Seletivo de Íons). Entretanto, a preparação de amostra pode ser um fator limitante na velocidade total da análise, uma vez que a ELL envolve várias etapas. Deste modo, numerosos esforços têm sido feito para melhorar as técnicas de ELL em função do consumo de solvente, do volume de amostra e do tempo de análise. Técnicas modernas, que possuem alta sensibilidade, empregam 50 - $100 \mu \mathrm{L}$ de plasma ao passo que 10 anos atrás usavam-se $5-10 \mathrm{~mL}$ de amostra biológica $^{32,33}$. Volumes pequenos de amostra requerem volumes pequenos de solventes para extração. Na tentativa de aumentar a velocidade total de análise foi necessário que a ELL fosse automatizada. Jemal et al. ${ }^{34}$ publicaram um trabalho comparando a ELL manual com a automatizada e mostraram que é possível uma diminuição significativa no tempo de preparo de amostra com o uso de sistemas automatizados, sem comprometer a exatidão e a precisão. Várias técnicas de ELL automáticas ou semi-automáticas têm surgido ${ }^{35}, 36$ possibilitando que números elevados de análises, até $2000 / 24 \mathrm{~h}$, sejam realizadas ${ }^{37,38}$.

\section{EXTRAÇÃO EM FASE SÓLIDA (EFS)}

Hoje em dia a extração em fase sólida é uma das ferramentas mais poderosas e mais empregadas para a extração e/ou pré-concentração de analitos presentes em matrizes complexas. Esta técnica foi revisada recentemente por Hennion ${ }^{39}$ e por Majors ${ }^{40}$.A EFS emprega sorventes recheados em cartuchos, nas formas de barril ou seringa, e os mecanismos de retenção são idênticos àqueles envolvidos em cromatografia líquida em coluna. Um cartucho típico é formado por um tubo de polipropileno contendo cerca de 50 a $500 \mathrm{mg}$ de sorvente, com $40-60 \mu \mathrm{m}$ de tamanho de partícula, fixado no tubo através de dois filtros. Em geral, os procedimentos de EFS contêm 5 etapas: i) ativação do sorvente para deixar os sítios ativos disponíveis; ii) condicionamento do sorvente com solvente adequado para ajustar as forças do solvente de eluição com o solvente da amostra; iii) introdução da amostra, quando ocorre a retenção do analito e às vezes de alguns interferentes; iv) limpeza da coluna para retirar os interferentes menos retidos que o analito; v) eluição e coleção do analito ${ }^{41}$.

Atualmente um número grande de sorventes são disponíveis comercialmente. Em geral, os materiais de recheio, empregados para EFS, são similares aos usados em cromatografia líquida. Assim, carvão ativado, alumina, sílica gel, silicato de magnésio (Florisil), fases quimicamente ligadas e polímeros, por exemplo, o copolímero de estireno entrecruzado com divinilbenzeno, têm sido empregados (Tabela 1). Dependendo do solvente de condicionamento e de eluição, os grupos mais frequentemente usados como sorventes à base de sílica quimicamente ligada podem ser divididos em 3 categorias: i) fase reversa (FR) quando o sorvente é menos polar que o solvente de eluição; ii) fase normal (FN) quando o solvente é menos polar que o sorvente e iii) troca iônica (TI). A Tabela 2 mostra um guia para seleção de sorventes a serem utilizados na $\mathrm{EFS}^{41}$.

Para aumentar a seletividade da extração os sorventes podem ser combinados das seguintes maneiras:

i) Dentro de um mesmo cartucho de extração, usando as chamadas fases mistas com vários grupos funcionais de características diferentes ligados ao mesmo suporte;

ii) Fazendo sucessivas extrações com cartuchos de diferentes recheios, passando o material eluido do primeiro cartucho para o segundo no modo "on-line" ou "off-line";

iii) Recheando o mesmo cartucho com diferentes sorventes, em camadas, resultando em uma coluna de extração tipo sanduíche.

Os recentes desenvolvimentos em EFS têm sido direcionados para a síntese de sorventes mais seletivos e para novas configurações cromatográficas. Alguns exemplos estão citados a seguir.

\section{Novos sorventes}

Fases mais seletivas, quimicamente ligadas à sílica (ou a outro suporte), têm sido preparadas. Um exemplo é a fase fenilboronato, Tabela 1, que seletivamente retém 1,2 cis-diol. Esta fase pode ser utilizada em análises de nucleosídeos, nucleotídeos, 
Tabela 1. Exemplos de sorventes utilizados em EFS.

\begin{tabular}{|c|c|c|}
\hline \multicolumn{3}{|c|}{ NÃO POLARES } \\
\hline $\mathrm{C} 18$ & Octadecilsilano & $\equiv \mathrm{Si}-\left(\mathrm{CH}_{2}\right)_{17}-\mathrm{CH}_{3}$ \\
\hline $\mathrm{C} 8$ & Octilsilano & $\equiv \mathrm{Si}-\left(\mathrm{CH}_{2}\right)_{7}-\mathrm{CH}_{3}$ \\
\hline $\mathrm{C} 2$ & Etilsilano & $\equiv \mathrm{Si}-\mathrm{CH}_{2}-\mathrm{CH}_{3}$ \\
\hline $\mathrm{C} 1$ & Metilsilano & $\equiv \mathrm{Si}-\mathrm{CH}_{3}$ \\
\hline $\mathrm{PH}$ & Fenilsilano & $\equiv \mathrm{Si}-\langle\square$ \\
\hline $\mathrm{CH}$ & Cicloexilsilano & $\equiv \mathrm{Si}-\triangle$ \\
\hline \multicolumn{3}{|c|}{ POLARES } \\
\hline FL & Florisil & $\mathrm{MgO}_{3} \mathrm{Si}$ \\
\hline $\mathrm{AL}$ & Alumina & $\mathrm{Al}_{2} \mathrm{O}_{3}$ \\
\hline $\mathrm{Si}$ & Sílica & $\equiv \mathrm{Si}-\mathrm{OH}$ \\
\hline $\mathrm{CN}$ & Cianopropilsilano & $\equiv \mathrm{Si}-\mathrm{CH}_{2}-\mathrm{CH}_{2}-\mathrm{CH}_{2}-\mathrm{CN}$ \\
\hline $2 \mathrm{OH}$ & Diolsilano & $\equiv \mathrm{Si}-\mathrm{CH}_{2}-\mathrm{CH}_{2}-\mathrm{CH}_{2}-\mathrm{O}-\mathrm{CH}_{2}-\underset{\mathrm{OH}}{\mathrm{CH}}-\underset{\mathrm{OH}}{\mathrm{CH}_{2}}$ \\
\hline $\mathrm{NH} 2$ & Aminopropilsilano & $\equiv \mathrm{Si}-\mathrm{CH}_{2}-\mathrm{CH}_{2}-\mathrm{CH}_{2}-\mathrm{NH}_{2}$ \\
\hline PSA & N-Propiletilenodiaminossilano & $\equiv \mathrm{Si}-\mathrm{CH}_{2}-\mathrm{CH}_{2}-\mathrm{CH}_{2}-\mathrm{NH}-\mathrm{CH}_{2}-\mathrm{CH}_{2}-\mathrm{NH}_{2}$ \\
\hline \multicolumn{3}{|c|}{ TROCA IÔNICA } \\
\hline SCX & Benzenossulfonilpropilsilano & $\equiv \mathrm{Si}-\mathrm{CH}_{2}-\mathrm{CH}_{2}-\varangle-\mathrm{SO}_{3}^{-} \mathrm{H}^{+}$ \\
\hline PRS & Sulfonilpropilsilano & $\equiv \mathrm{Si}-\mathrm{CH}_{2}-\mathrm{CH}_{2}-\mathrm{CH}_{2}-\mathrm{SO}_{3}^{-} \mathrm{Na}^{+}$ \\
\hline CBA & Carboximetilsilano & $\equiv \mathrm{Si}-\mathrm{CH}_{2}-\mathrm{CH}_{2}-\mathrm{COOH}$ \\
\hline DEA & Dietilaminopropilsilano & $\equiv \mathrm{Si}-\mathrm{CH}_{2}-\mathrm{CH}_{2}-\mathrm{CH}_{2}-\mathrm{N}\left(\mathrm{CH}_{2}-\mathrm{CH}_{3}\right)_{2}$ \\
\hline SAX & Trimetilaminopropilsilano & $\equiv \mathrm{Si}-\mathrm{CH}_{2}-\mathrm{CH}_{2}-\mathrm{CH}_{2}-\mathrm{N}^{+}\left(\mathrm{CH}_{3}\right)_{3} \mathrm{Cl}^{-}$ \\
\hline PSA & N-Propiletilenodiaminossilano & $\equiv \mathrm{Si}-\mathrm{CH}_{2}-\mathrm{CH}_{2}-\mathrm{CH}_{2}-\mathrm{NH}-\mathrm{CH}_{2}-\mathrm{CH}_{2}-\mathrm{NH}_{2}$ \\
\hline \multicolumn{3}{|c|}{ COVALENTE } \\
\hline PBA & Ácido fenilborônico & $\equiv \mathrm{Si}-\mathrm{CH}_{2}-\mathrm{CH}_{2}-\mathrm{CH}_{2}-\mathrm{NH}-\longrightarrow \mathrm{B}(\mathrm{OH})_{2}$ \\
\hline
\end{tabular}

Tabela 2. Guia para seleção de sorventes a serem utilizados em EFS ${ }^{41}$.

\begin{tabular}{|c|c|c|c|c|}
\hline Aplicações & Grupo funcional do analito & Matriz & Sorventes & Solvente de eluição \\
\hline $\begin{array}{l}\text { Extração não-polar } \\
\text { Abuso de drogas } \\
\text { Peptídeos } \\
\text { Pesticidas } \\
\text { Monitoramento de droga } \\
\text { terapêutica }\end{array}$ & $\begin{array}{c}\text { Grupos hidrofóbicos } \\
\text { Anéis aromáticos } \\
\text { Cadeias alquil }\end{array}$ & $\begin{array}{c}\text { Aquosa } \\
\text { Água } \\
\text { Tampões } \\
\text { Fluidos biológicos }\end{array}$ & $\begin{array}{l}\text { Octadecil } \\
\text { Octil } \\
\text { Etil } \\
\text { Cicloexil } \\
\text { Fenil } \\
\text { Cianopropil }\end{array}$ & $\begin{array}{c}\text { Metanol } \\
\text { Acetonitrila } \\
\text { Acetato de etila } \\
\text { Clorofórmio } \\
\text { Metanol acidificado } \\
\text { Hexano }\end{array}$ \\
\hline $\begin{array}{l}\text { Extração polar } \\
\text { Metabólitos de Vitamina D } \\
\text { Separações de líquidos } \\
\text { Carboidratos } \\
\text { Fenóis }\end{array}$ & $\begin{array}{c}\text { Grupos hidrofílicos } \\
\text { Hidroxilas } \\
\text { Aminas } \\
\text { Heteroátomos }\end{array}$ & $\begin{array}{l}\text { Não polares } \\
\text { Hexano } \\
\text { Óleos } \\
\text { Clorofórmio } \\
\text { Lipídeos }\end{array}$ & $\begin{array}{l}\text { Cianopropil } \\
\text { Diol } \\
\text { Sílica } \\
\text { Aminopropil } \\
\text { Amina }\end{array}$ & $\begin{array}{l}\text { Metanol } \\
\text { Isopropanol } \\
\text { Acetona }\end{array}$ \\
\hline $\begin{array}{l}\text { Extração por troca catiônica } \\
\text { Catecolaminas } \\
\text { Herbicidas } \\
\text { Fármacos }\end{array}$ & $\begin{array}{c}\text { Cátion } \\
\text { Aminas } \\
\text { Pirimidinas }\end{array}$ & $\begin{array}{c}\text { Aquosa } \\
\text { Agua } \\
\text { Tampões ácidos } \\
\text { Fluidos biológicos }\end{array}$ & $\begin{array}{l}\text { Trocador fortemente ou } \\
\text { fracamente catiônico }\end{array}$ & $\begin{array}{l}\text { Tampões básicos } \\
\text { Tampões com alta } \\
\text { força iônica }\end{array}$ \\
\hline $\begin{array}{l}\text { Extração por troca aniônica } \\
\text { Ácidos orgânicos } \\
\text { Vitaminas } \\
\text { Ácidos Graxos } \\
\text { Fosfatos }\end{array}$ & $\begin{array}{c}\text { Ânions } \\
\text { Ácidos Carboxílicos } \\
\text { Ácidos Sulfônicos } \\
\text { Fosfatos } \\
\text { Aquoso }\end{array}$ & $\begin{array}{c}\text { Aquosa } \\
\text { Agua } \\
\text { Tampões básicos } \\
\text { Fluidos biológicos }\end{array}$ & $\begin{array}{l}\text { Trocador fortemente ou } \\
\text { fracamente catiônico }\end{array}$ & $\begin{array}{l}\text { Tampões ácidos } \\
\text { Tampões com alta } \\
\text { força iônica }\end{array}$ \\
\hline
\end{tabular}


carboidratos e catecolaminas. Este sorvente foi aplicado na extração seletiva de nucleosídeos modificados em soro e urina de pacientes portadores de diversos tipos de câncer ${ }^{42,43}$.

A fase sólida também pode ser quimicamente modificada com um grupo reativo ou pode ser carregada com uma solução contendo um composto reativo para derivatizar o analito. Um exemplo é a reação de fenobarbitona com brometo de pentafluorbenzila impregnado previamente na fase sólida ${ }^{44}$.

Recentemente, extrações altamente seletivas baseadas em colunas recheadas com suportes contendo um anticorpo ou com polímeros impressos molecularmente, conhecidos como MIP, têm sido desenvolvidas. As etapas de extração, concentração e isolamento são possíveis em um único passo. As fases de imunoafinidade, onde um anticorpo específico é imobilizado em um suporte sólido, tal como agarose ou sílica, também têm sido utilizadas em análises de amostras de importância biológica. Um exemplo é a determinação de insulina em amostras de plasma, onde a extração seletiva é realizada em uma coluna recheada com o seu anticorpo anti-insulina (nome original AE9D6) ${ }^{45}$. Os MIP são obtidos através da preparação de polímeros com sítios de reconhecimento sintéticos e têm uma seletividade pré-determinada para um ou mais analitos ${ }^{46-50}$. Estes sítios de reconhecimento são obtidos pelo arranjo de monômeros funcionais polimerizáveis ao redor das moléculas do analito. Assim são formados complexos, através de interação molecular, entre o analito e o monômero precursor. Os complexos são fixados através de reações de entrecruzamento de polímeros. A remoção do analito da matriz polimérica forma lacunas (sítios de reconhecimento) que irão exibir afinidade pelo analito. O potencial deste tipo de material é alto, uma vez que oferece resistência mecânica à alta temperatura e à pressão e é inerte frente a condições extremas de ácidos, bases, íons metálicos e solventes orgânicos. Estas características são altamente favoráveis para serem utilizadas em análises de rotina. Entretanto a aplicação deste material em análises biológicas ainda é limitada; alguns exemplos de aplicações deste material são análise de drogas em plasma e urina ${ }^{51-55}$.

Um outro material, denominado fase de acesso restrito, possui uma superfície hidrofílica biocompatível na parte externa e hidrofóbica no interior dos poros da partícula do sorvente. O mecanismo de separação é baseado em uma combinação de exclusão e partição. As moléculas grandes, tais como proteínas, não conseguem penetrar nos poros e eluem rapidamente, enquanto as moléculas pequenas entram nos poros e são retidas, para posterior eluição e análise, Figura 1. Este tipo de material tem sido usado para análise direta, sem remoção prévia de proteínas, de amostras de plasma e soro ${ }^{56,57}$.

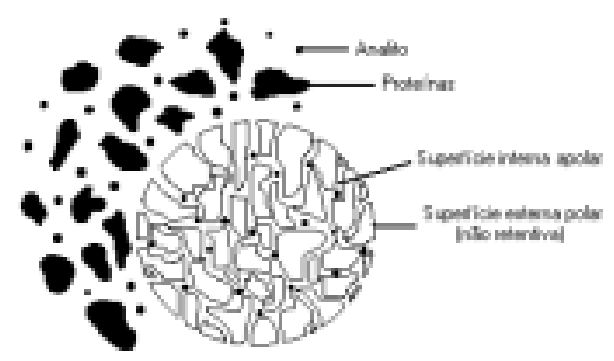

Figura 1. Fase de acesso restrito.

\section{Novas configurações experimentais para EFS}

\section{Extração em Discos}

O segundo formato de EFS mais utilizado depois do cartucho é o disco (ou membrana carregada de partícula). Neste tipo de EFS, as partículas ativas são imobilizadas em uma matriz inerte e estável de microfibrilas de politetrafluoretileno (PTFE) ou vidro.
A extração em discos foi originalmente introduzida para extração de traços de materiais orgânicos em água ${ }^{58}$. Um disco típico, $47 \mathrm{~mm}$ de diâmetro e $0,5 \mathrm{~mm}$ de espessura, contém 500 $\mathrm{mg}$ de sorvente, por exemplo, partículas de C-8 ou C-18, de $8 \mu \mathrm{m}$ de diâmetro de partícula e $6 \mathrm{~nm}$ de poro, imobilizadas no suporte ${ }^{59}$. O diâmetro do disco é escolhido de acordo com o volume de amostra. Os discos são disponíveis em vários diâmetros, 4 a $90 \mathrm{~mm}$. Diâmetros de 25 a $47 \mathrm{~mm}$ são particularmente úteis na análise de urina, pois volumes relativamente grandes podem ser extraídos (10 a $50 \mathrm{~mL}$ ). Diâmetros menores são usados para determinação de drogas em plasma ou soro, onde a evaporação do efluente não é aconselhável.

Os discos possuem uma série de vantagens devido ao seu formato, tais como leito mais homogêneo, pressões menores durante a aplicação da amostra e na eluição, ausência de caminhos preferenciais, maior capacidade para o analito, melhor repetibilidade e reprodutibilidade, vazões mais altas e menores volumes de eluentes para a dessorção. O melhor desempenho dos discos é devido ao tamanho menor da partícula, que proporciona uma transferência de massa mais rápida. Uma das desvantagens do uso de discos é que a etapa de condicionamento é mais crítica. Diferente da EFS em cartuchos, a secagem do disco deve ser evitada, pois, devido à grande área superficial, uma interface ar/água é formada facilmente, resultando em um decréscimo das recuperações. Da mesma forma que os cartuchos, os poros dos discos podem ser obstruídos quando se extrai amostras contendo uma concentração relativamente alta de macromoléculas ou de material particulado. Assim, é aconselhável filtrar as amostras aquosas antes da extração ou usar pré-filtros inertes.

Para aumentar a seletividade ou a capacidade dos discos, pode utilizar a técnica de empilhamento. Empilhando vários discos de mesmo sorvente irá aumentar a capacidade e se os sorventes forem diferentes, tem-se a retenção de compostos com características diferentes.

O processo de extração pode ser realizado de duas maneiras:

i) A mais comum é empregar o mesmo aparelho utilizado em CLAE para filtração de solventes e passar a amostra através do disco sob vácuo. Os analitos são retidos e são removidos com um volume adequado de solvente;

ii) O disco é suspendido na amostra líquida, por um período de tempo controlado, em seguida é seco e os analitos são dessorvidos em um outro solvente apropriado.

Nos últimos tempos, os discos estão tendo uma grande aceitação em análises biomédicas. Isto se deve à necessidade de métodos que usem quantidades reduzidas de amostra; possuam poucas etapas de extração/pré-concentração e não consumam um tempo excessivo. $\mathrm{O}$ volume de eluição baixo $(30$ a $100 \mu \mathrm{L})$ permite, em alguns casos, fazer a injeção direta no sistema cromatográfico. Em outros casos uma simples diluição com água destilada é suficiente para injeção. Isto não somente elimina o tempo requerido para evaporação do solvente, mas também evita qualquer perda devido à transferência de amostra. Os avanços recentes desta técnica são descritos por Blevins e Hall ${ }^{60}$.

\section{Técnicas de extração "on-line"}

Os processos de EFS podem ser realizados em dois modos: "off-line" ou "on-line". Na configuração "on-line", o sistema de extração em fase sólida faz parte de um sistema de CLAE, e é frequentemente inserido na alça de amostragem, sendo, após a coleta, conectado diretamente na linha de alta pressão da fase móvel que atua como eluente da amostra.

Faz parte da extração "on-line" uma técnica chamada de comutação de colunas, que inclue todos os métodos nos quais a direção do fluxo da fase móvel é alterado por meio de uma válvula rotatória, onde o efluente de uma coluna é desviado para uma outra coluna após um certo intervalo de tempo. A primeira coluna é frequentemente de baixa eficiência e faz um enriquecimento ou pré-concentração da amostra. A fração con- 

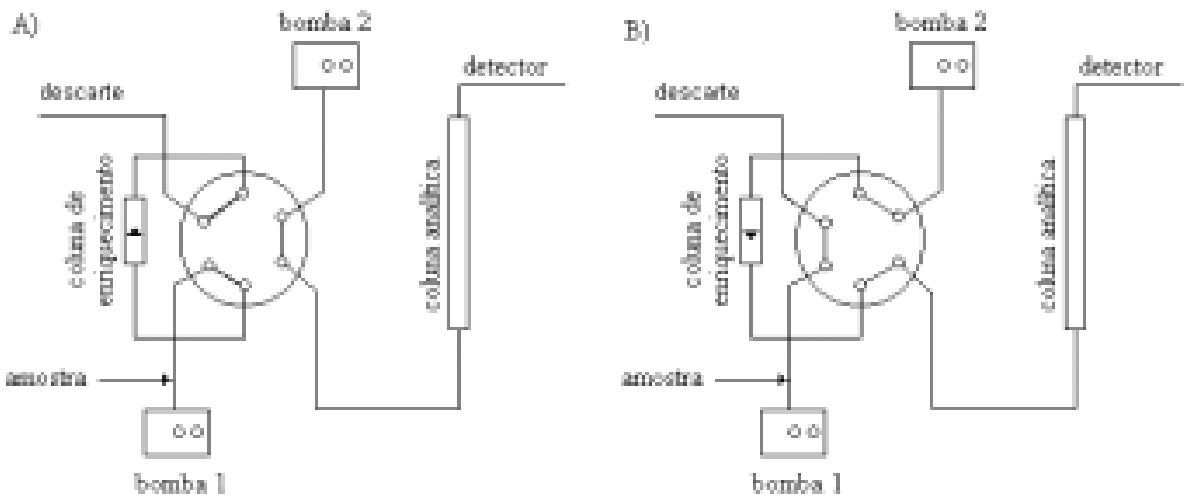

Figura 2. Diagrama do sistema "comutação de colunas". A) Pré-concentração e B) Dessorção e separação cromatográfica.

tendo o analito é transferida para uma segunda coluna que possui alta eficiência. O arranjo mais comum está mostrado na Figura 2. Quando o injetor está na posição "carregar", a amostra é bombeada pela bomba 1 através da pré-coluna, onde os analitos são retidos. Simultaneamente, a fase móvel é bombeada pela bomba 2 passando diretamente para a coluna analítica. Quando a etapa de pré-concentração termina, a válvula de injeção é colocada na posição "injetar" e então a fase móvel passa pela pré-coluna e remove os analitos, enviando-os para a coluna analítica, onde são separados. Uma revisão sobre o uso desta técnica aplicada em análises de drogas presentes em fluidos biológicos foi publicada por Campíns-Falcó et al. ${ }^{61}$. Um exemplo do uso de comutação de colunas é a determinação de ácido úrico e creatinina em fluidos biológicos ${ }^{62}$.

Uma outra configuração para tratamento de amostras "on-line" é o acoplamento de cromatografia líquida com cromatografia gasosa (CL-CG). A CL é usada para fazer uma pré-concentração ou enriquecimento de traços, enquanto a separação de alta resolução (em coluna capilar) e a detecção são feitas por CG. Neste procedimento o tempo gasto na preparação de amostras é mínimo. Um exemplo de aplicação desta técnica é a determinação de beta bloqueadores em amostras de plasma e em urina ${ }^{63,64}$.

\section{Microextração em fase sólida (MEFS)}

A microextração em fase sólida é uma técnica moderna desenvolvida por Arthur e Pawliszyn ${ }^{65}$. Neste procedimento é empregada uma fibra ótica, de sílica fundida, recoberta com um filme fino de um polímero (e.g., polidimetilsiloxano, poliacrilato ou carbowax) ou de um adsorvente sólido (e.g., carvão ativo microparticulado). Esta fibra ótica, que é uma fase extratora, é acondicionada dentro da agulha de uma microseringa, para a extração dos analitos ${ }^{66}$.

A extração pode ser feita de duas maneiras:

i) Mergulhando a fibra diretamente na solução da amostra. Durante a extração a amostra é agitada e o tempo é controlado. Os analitos são concentrados por 2 a $15 \mathrm{~min}$; após esta etapa a fibra é recolhida para dentro da agulha;

ii) Através da técnica de "headspace", na qual a amostra é frequentemente aquecida e os componentes voláteis são adsorvidos na fibra, conforme Figura 3.

Após a extração os analitos presentes na fibra são dessorvidos termicamente pela sua introdução no injetor aquecido de um cromatógrafo a gás.

As vantagens do método de MEFS são que o procedimento analítico é mais simples e mais rápido que ELL e EFS, em geral extratos mais limpos são obtidos, não usa solventes para a eluição. Por outro lado o analito necessita ser volátil e termicamente estável para ser dessorvido e determinado por CG.

Este método tem sido revisado ${ }^{67}$ e vários artigos têm sido publicados reportando o uso deste sistema em matrizes bioló-

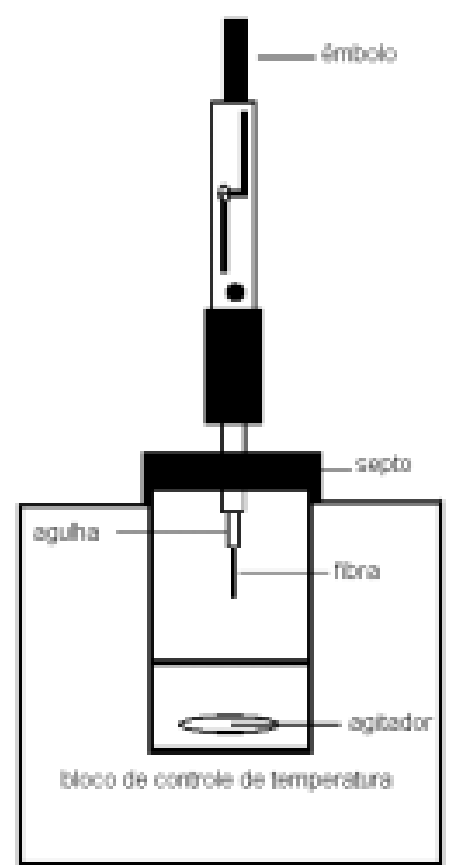

Figura 3. Ilustração esquemática do método MEFS - "Headspace".

gicas. Alguns exemplos são análise de etanol em sangue ${ }^{68}$, pesticidas em urina e sangue ${ }^{69}$, entorpecentes em urina ${ }^{70}$ e antidepressivos em sangue $\mathrm{e}^{71}$.

\section{EXTRAÇÃO COM FLUIDO SUPERCRÍTICO (EFSC)}

O fluido supercrítico é o estado da matéria acima da temperatura crítica e da pressão crítica onde o vapor e o líquido têm a mesma densidade e o fluido não pode ser liquefeito pelo simples aumento da pressão. Dentro de uma variedade de fluidos supercríticos, o $\mathrm{CO}_{2}$ é o mais utilizado, pois não é caro, é relativamente não-tóxico, não-inflamável, tem, comparativamente a outros fluidos, baixa temperatura crítica, $31,3^{\circ} \mathrm{C}$, e pressão crítica, 7,4 MPa, além de ser facilmente removido após a extração ${ }^{72}$.

Em EFSC o fracionamento pode ser feito através de mudança de pressão e/ou temperatura. Modificadores, tal como metanol, também podem ser empregados para mudar a seletividade de um fluido supercrítico. Comparados com solventes líquidos, fluidos supercríticos têm viscosidades mais baixas e maiores coeficientes de difusão de solutos, o que facilita a transferência de massa durante a extração.

A extração pode ser feita em matrizes sólidas, semi-sólidas ou líquidas. A extração com fluido supercrítico tem mostrado 
ser uma alternativa viável aos métodos tradicionais de extração, ELL e EFS, para análises de fluidos biológicos. As vantagens desta técnica são que a EFSC elimina o tempo gasto com a remoção de solventes, que são utilizados nas técnicas convencionais de preparação de amostras; não utiliza solventes orgânicos, que são normalmente tóxicos, diminuindo assim os riscos de manipulação e minimizando os custos. Entretanto, as desvantagens são que o analito deve ser solúvel no fluido supercrítico, o que pode ser contornado através da adição de aditivos no eluente, e que a etapa de remoção do analito da amostra pelo fluido supercrítico é a etapa mais problemática do processo. As estratégias para a extração seletiva de analitos em amostras sólidas foram descritas por Levy ${ }^{72}$.

A EFSC de drogas em plasma pode ser feita combinada com EFS $^{73}$ ou diretamente na amostra ${ }^{74}$. Também tem sido reportada na literatura a extração de compostos organoclorados (PCB) em leite materno ou soro através de EFSC combinada com EFS acopladas, de forma "on-line", com CG (EFSC-CG) ${ }^{75}$.

\section{TÉCNICAS DE EXTRAÇÃO COM MEMBRANAS}

\section{Membranas sólidas}

Esta técnica foi recentemente revisada por van der $\mathrm{Merbel}^{76}$. Uma membrana é uma barreira seletiva entre duas fases, conforme mostra a Figura 4, sendo que a fase 1 é chamada de doadora e a fase 2 de receptora. A separação é obtida devido à capacidade da membrana de transportar alguns componentes da fase doadora para a receptora mais rapidamente que outros. Em geral a membrana nunca é uma barreira semi-permeável perfeita. As membranas podem ser classificadas baseadas na estrutura e no mecanismo de separação. Quanto à estrutura, as membranas podem ser porosas ou não porosas e simétricas ou assimétricas, como pode ser visualizado na Figura 5. O fenômeno que ocorre quando uma espécie passa através de um meio é chamado de permeação. Os mecanismos envolvidos na permeação baseiamse em forças dirigidas: diferença de concentração, diferença de potencial elétrico ou diferença de pressão. Neste trabalho serão descritas apenas as técnicas que levam ao fluxo molecular baseadas em forças dirigidas de concentração (diálise) e de pressão (ultrafiltração), pois foram encontradas pouquíssimas aplicações em amostras biológicas da técnica baseada em diferença de potencial elétrico (eletrodiálise) e os trabalhos publicados ${ }^{77-80}$ não apresentaram aplicação para uso em análises de rotina.

\section{Diálise}

Na diálise os solutos difundem do lado doador para o lado receptor da membrana como resultado de um gradiente de concentração e é principalmente utilizada para a separação de solutos de massa molar baixa dos de massa molar alta.

Para a obtenção de recuperações elevadas por unidade de tempo deve-se ter uma membrana com grande área superficial, um grande coeficiente de difusão, uma camada fina e uma baixa tortuosidade. Entretanto, a maior desvantagem desta técnica é que, com o aumento do tempo, o gradiente de concentração e, consequentemente, o fluxo decrescem lentamente até se tornarem zero. Além de ser lento, as recuperações são de somente

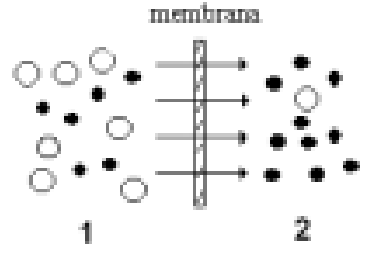

Figura 4. Representação esquemática de uma membrana: 1) fase doadora e 2) fase receptora.

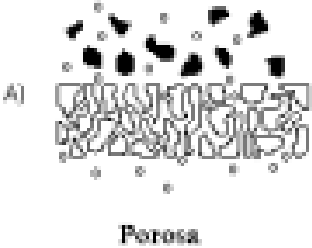

Porosa

Simetrica

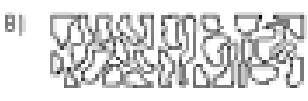

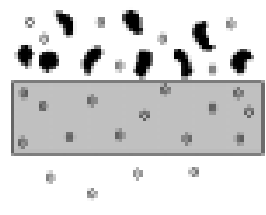

Nio porosa

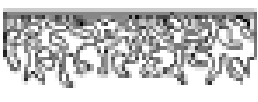

Assimétrica.
Figura 5. Representação esquemática de: A) membranas porosas e não porosas e B) membranas porosas simétricas e assimétricas.

$50 \%$ para volumes iguais de doador e receptor. Portanto ela deve ser usada quando a concentração do analito é alta ou quando a detecção não constitui um problema.

Para contornar este problema, a diálise contínua é aplicada. Neste caso o soluto que atravessa a membrana é retirado continuamente do compartimento receptor, mantendo, consequentemente, o gradiente de alta concentração e, portanto, um fluxo maior é obtido. A diálise contínua é mais rápida e, em princípio, o analito pode ser transferido quantitativamente para o sistema cromatográfico. Uma desvantagem inerente ao processo contínuo é a alta diluição do analito que requer que uma coluna de pré-concentração seja incluída na alça de amostragem do injetor cromatográfico.

Polímeros hidrofílicos são os mais utilizados como material para diálise, especialmente celulose regenerada e acetato de celulose, que são manufaturados em diferentes configurações, são resistentes a vários modificadores orgânicos e podem ser utilizados no intervalo de $\mathrm{pH}$ de 2 a 8 . Entretanto, estes materiais não são muito estáveis química e termicamente e estão sujeitos a ataques de bactérias. Tem sido mostrado também que essas membranas interagem com diversas classes de solutos orgânicos em soluções aquosas ${ }^{81}$. Um outro parâmetro importante é o chamado corte de massa molar nominal, que é definido como a menor massa molar do soluto que é retida $90 \%$ ou mais na solução doadora. $\mathrm{O}$ termo nominal é usado porque a forma e a carga do soluto irão afetar a sua velocidade de migração. Membranas com cortes de 100 a 500.000 são comercialmente disponíveis e alguns exemplos estão mostrados na Tabela 3. A espessura da membrana é normalmente de 10 a $200 \mu \mathrm{m}$.

Tabela 3. Exemplos típicos de membranas para diálise disponíveis comercialmente.

\begin{tabular}{|c|c|c|c|c|}
\hline Material & Nome Comercial & Fornecedor & Estrutura & $\begin{array}{l}\text { Corte de Massa } \\
\text { Molar Nominal }\end{array}$ \\
\hline acetato de celulose & - & Gilson (França) & $\mathrm{MP}^{*}$ & 15.000 \\
\hline éster de celulose & Spectra/Por & Spectrum (EUA) & $\mathrm{MP}^{*}$ & 100 \\
\hline celulose regenerada & Spectra/Por & Spectrum (EUA) & $\mathrm{MP}^{*}$ & $1000-500.000$ \\
\hline celulose regenerada & Visking & Reichelt (Alemanha) & $\mathrm{MP}^{*}$ & $10.000-20.000$ \\
\hline celulose regenerada & Spectra/Por & Spectrum (EUA) & bolsa & $6.000-500.000$ \\
\hline
\end{tabular}

* MP = membrana planar 


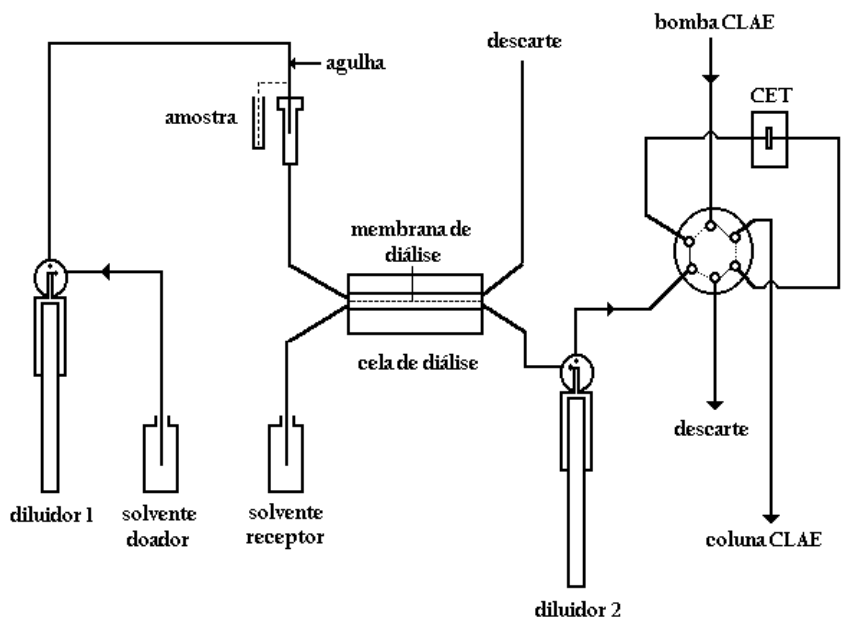

Figura 6. Representação esquemática de um sistema ASTED da Gilson. CET = coluna de enriquecimento de traços.

Um exemplo interessante citado na literatura é a análise enantiosseletiva de drogas em plasma humano através de diálise, pré-concentração em uma coluna curta, seguido de separação por CLAE em coluna quiral ${ }^{82}$.

Um equipamento para enriquecimento sequencial automático de traços de dialisados (ASTED, Gilson), combinando a forma "on-line" de diálise com CLAE, tem sido usado com sucesso na análise de compostos presentes em matrizes biológicas comple$\operatorname{xas}^{83-85}$. Este sistema, Figura 6, consiste de um amostrador automático equipado com dois diluidores (1 e 2) adaptados a uma seringa de $1 \mathrm{~mL}$, uma válvula rotatória de 6 portas e uma cela de diálise que usa uma membrana de acetato de celulose de 15.000 Da. Antes de chegar na cela de diálise, a amostra pode sofrer diluições, adição de padrão interno ou reações químicas (derivatização). A amostra é carregada para o compartimento doador da cela de diálise por meio do diluidor 1 . O solvente receptor e os compostos de massa molar baixa se difundem através da membrana e são enviados continuamente para a coluna de enriquecimento de traços (CET) através do diluidor 2. A diálise pode ocorrer nos modos: móvel, estagnada ou pulsada. Após o término da etapa de enriquecimento de traços, aciona-se a válvula injetora para a posição "injetar" e os compostos, que ficaram retidos na CET são eluidos para a coluna analítica do sistema cromatográfico (CLAE), onde são analisados. Durante a análise cromatográfica a cela de diálise é purgada e a CET é regenerada para que possa injetar a amostra seguinte. Este sistema permite que mais de 100 amostras sejam analisadas em um período de 24 h. Embora este método forneça menor tempo de diálise, o problema de interação de drogas com a membrana é um fator limitante ${ }^{86}$.

\section{Ultrafiltração}

Na ultrafiltração tanto o soluto como o solvente são permeados na membrana através de um gradiente de pressão. Baseados no tamanho do poro, as membranas podem ser subdivididas em hiperfiltração ou osmose reversa $(0,1-1 \mathrm{~nm})$, ultrafiltração (1$100 \mathrm{~nm})$ e microfiltração $(100-1.000 \mathrm{~nm})$.

A ultrafiltração tem sido largamente utilizada para a remoção de proteínas e de outras macromoléculas em análises de amostras biológicas ${ }^{87-89}$, pois tem uma série de vantagens: é uma técnica simples, as membranas são disponíveis comercialmente (Tabela 4) e não possui problemas de diluição da amostra e nem de troca de solvente.

Um problema comum que ocorre é quando a solução a ser filtrada contém solutos que não podem passar pela membrana. Neste caso, há a formação de uma camada de gel devido ao acúmulo de solutos retidos, que fornece uma resistência adicional à transferência de massa. Este problema pode ser minimizado pela remoção constante destes solutos da superfície da membrana. Outro inconveniente é que pode ter interações indesejáveis das moléculas com a membrana ${ }^{86}$, tais como proteína-proteína e proteína-membrana ${ }^{90}$.

\section{Membranas líquidas}

Técnicas de extração através de membranas líquidas têm sido descritas recentemente na literatura ${ }^{91-96}$. Estes sistemas são particularmente interessantes para o preparo de amostras, que são analisadas posteriormente por CLAE com fase reversa, onde não é recomendado injetar amostras dissolvidas em solventes apolares. Os dois modos principais de extração através de membranas líquidas estão descritos a seguir:

\section{Microextração com solvente com extração posterior simultânea (MES/EPS)}

A microextração com solvente com extração posterior simultânea (MES/EPS) utiliza uma membrana líquida orgânica não suportada $(\leq 80 \mu \mathrm{L})$, mantida dentro de um anel de PTFE, situado entre duas fases aquosas, uma doadora (onde se aplica a amostra) e a outra receptora (de menor volume que a doadora). A fase doadora é agitada, por meio de um agitador magnético, para facilitar o processo de transferência de massa. Neste sistema os analitos não-carregados são extraídos da fase doadora para a fase orgânica, e simultaneamente a fase receptora extrai os compostos da fase orgânica. Há vários parâmetros que governam estas extrações sendo mais importante o $\mathrm{pH}$. Após a extração, uma alíquota da fase receptora é injetada diretamente no sistema de CLAE para quantificação. Extração quantitativa, com um fator de enriquecimento de cinco vezes ou mais, pode ser

Tabela 4. Exemplos de membranas disponíveis comercialmente para ultrafiltração.

\begin{tabular}{|c|c|c|c|c|c|}
\hline $\begin{array}{l}\text { MEMBRANA } \\
\text { Whatman } 10.000\end{array}$ & $\begin{array}{l}\text { CITC }^{1} \\
80-95 \%\end{array}$ & $\begin{array}{c}\text { PEPSINA }^{2} \\
90-95 \%\end{array}$ & $\begin{array}{c}\text { OVOALBUMINA }^{3} \\
>95 \%\end{array}$ & \multicolumn{2}{|c|}{$\begin{array}{l}\mathrm{ASB}^{4} \\
>95 \%\end{array}$} \\
\hline MEMBRANA & CITC & $\mathrm{AQTG}^{5}$ & OVOALBUMINA & ASB & $\mathrm{GG}^{6}$ \\
\hline Whatman 30.000 & $50-70 \%$ & $45-60 \%$ & $70-95 \%$ & $>95 \%$ & $>95 \%$ \\
\hline MEMBRANA & OVOALBUMINA & ASB & GG & $\mathrm{APO}^{7}$ & TIRO $^{8}$ \\
\hline Whatman 50.000 & $25-60 \%$ & $80->95 \%$ & $>95 \%$ & $>95 \%$ & $>95 \%$ \\
\hline Whatman 100.000 & $0-20 \%$ & $0-20 \%$ & $>95 \%$ & $>95 \%$ & $>95 \%$ \\
\hline Whatman 300.000 & - & $0-20 \%$ & $70-90 \%$ & $40-70 \%$ & $>95 \%$ \\
\hline Whatman 500.000 & $0-10 \%$ & $0-20 \%$ & $0-20 \%$ & $0-20 \%$ & $>95 \%$ \\
\hline
\end{tabular}

onde: 1 -CITC = Citocromo C (12.500); 2-Pepsina (34.500); 3- Ovoalbumina, (42.000); 4-ASB = Albumina Soro Bovina (67.000); 5-AQTG = Alfa Quimotripsinogênio (24.500); 6-GG = Gama Globulina (160.000); 7-APO = Apoferritina (480.000); 8-TIRO= Tiroglobulina (660.000). 
obtida facilmente. Esta técnica, por empregar pequenos volumes de amostra, de 0,3 a 1,5 mL, é muito interessante para fluidos biológicos ${ }^{91,92}$

\section{Extração em líquido suportado em membrana (ELSM)}

A técnica de extração em líquido suportado em membrana consiste de um líquido orgânico sorvido sobre uma membrana porosa fina, a qual forma uma barreira entre duas fases aquosas. O princípio desta técnica é o mesmo descrito no item anterior, entretanto a fase orgânica é suportada por uma membrana.

O uso de ELSM para a remoção de compostos orgânicos ionizáveis de soluções aquosas é uma alternativa promissora em relação à ELL e à EFS, devido à seletividade alta e às vazões relativamente rápidas que podem ser obtidas. Comparada a membranas poliméricas, esta técnica oferece velocidades de transferência de massa mais rápidas e a possibilidade de utilização de grande variedade de líquidos orgânicos e aditivos, sem comprometimento da estabilidade da membrana ${ }^{93}$. Esta técnica foi revisada recentemente por Jönsson e Mathiasson ${ }^{94,95}$. Um exemplo da aplicação desta técnica em fluidos biológicos é a extração de drogas anestésicas em urina com posterior determinação por CLAE com detector eletroquímico ${ }^{96}$.

\section{CONCLUSÕES}

Apesar do surgimento de técnicas modernas de separação, onde se pode obter alta seletividade e sensibilidade, em termos de detecção, para um dado analito (ou classe), presente em matrizes complexas, o preparo de amostra ainda é necessário e é a etapa mais problemática da análise. Há um número enorme de publicações nesta área e este artigo apresenta o estado da arte em termos de técnicas de extração e/ou concentração de compostos presentes em fluidos biológicos.

Em geral, mais de um tipo de técnica de extração e/ou concentração pode ser empregada para uma certa amostra. A escolha da técnica de extração e/ou concentração a ser utilizada deve levar em conta as seguintes características: i) ser simples; ii) ser rápida; iii) ter custo baixo; iv) fornecer extratos relativamente livres de interferentes; v) ter recuperações altas, com boa exatidão e precisão, para os analitos de interesse.

As inovações nos métodos de preparo de amostra estão voltadas, principalmente, para a automação e miniaturização e vários fabricantes têm disponibilizado sistemas automáticos de preparo de amostra, particularmente na área de extração em fase sólida, que é a técnica mais utilizada atualmente ${ }^{97}$. Estas técnicas automatizadas são úteis quando um volume grande de amostras deve ser processado ou quando o analista fica exposto a algum tipo de risco ao manipular as amostras. Entretanto equipamentos automáticos são, relativamente, caros e deve-se levar em conta o custo/benefício.

O método de preparação de amostra selecionado juntamente com a etapa de análise cromatográfica devem ser validados para assegurar a sua qualidade e confiança.

Os vários métodos de extração e/ou concentração de analitos encontrados em fluidos biológicos apresentam as suas vantagens e desvantagens, cabendo ao usuário analisá-los e optar por aquele que mais lhe convier.

\section{REFERÊNCIAS}

1. Drummer, O. H.; J. Chromatogr. B. 1999, 733, 27.

2. Polettini, A.; J. Chromatogr. B. 1999, 733, 47.

3. Hubert, Ph.; Ceccato, A.; Chiap, P.; Toussaint, B.; Crommen, J.; STP Pharma Prat. 1999, 9, 160.

4. Berrueta, L. A.; Gallo, B.; Vicente, F.; Chromatographia 1995, 40, 474

5. Snyder, L. R.; Kirkland, J., J.; Glajch, J. L.; Practical HPLC Method Development, John Wiley and Sons, New York, 1997, p. 110.
6. Badcock, N. R. e Zoanetti, G. D.; Ann. Clin. Biochem. 1996, 33, 75 .

7. Meng, Q. C.; Kramer, T. H.; Arhur, G. R.; Kim, P. S.; Ferrante, F. M.; Region Anesth. Pain M. 1999, 24, 242.

8. Le Solleu, H.; Demotes-Mainard, F.; Vincon, G.; Bannwarth, B.; J. Pharm. Biomed. Anal. 1993, 11, 771.

9. Mariot, R.; Zanglirolami, L.; J. Chromatogr. B 1996, 677, 190.

10. Benhaumou-Batut, F.; Demotes-Mainard, F.; Labat, L.; Vincon, G.; Bannwarth, B.; J. Pharm. Biomed. Anal. 1994, 12, 931.

11. Beal, J. L; Tett, S. E.; J. Chromatogr. B 1998, $715,409$.

12. Lo, D.; Chao, T.; Ng-Ong, S; Yao, Y.; Koh, T.; Forensic Sci. Int. 1997, 90, 205.

13. Ojanperä, I.; Rasanen, J.; Vuori, E.; J. Anal. Toxicol. 1991, 15, 204

14. Theurillat, R.; Thormann, W.; J. Pharm. Biomed. Anal. 1998, 18,751 .

15. Koves, E. M.; Wells, J.; J. Forensic Sci. 1992, 37,42.

16. Koves, E. M.; J. Chromatogr. A 1995, 692, 103.

17. Rieck, W.; Platt., D., J. Chromatogr. B 1992, 578, 259.

18. Chiba, K.; Horii, H.; Chiba, T; Kato, Y.; Hirano, T.; Ishizaki, T.; J. Chromatogr. B 1995, 668, 77.

19. Turcant, A.; Premel-Cabic, A.; Cailleux, A.; Allain, P.; Clin. Chem. 1991, 37, 1210.

20. Dawling, S.; Ward, N.; Essex, E. G.; Widdop, B.; Ann. Clin. Biochem. 1990, 27, 473.

21. Maurer, H. H.; Arlt, J. W.; Kraemer, T.; Schimitt, C. J.; Weber, A. A.; Arch. Toxicol. Suppl. 1997, 19, 189.

22. Lillsunde, P.; Michelson, L.; Forsstrom, T.; Korte, T.; Schultz, E.; Ariniemi, K.; Portman, M.; Sihvonen, M. L.; Seppala, T.; Forensic Sci. Int. 1996, 77, 191.

23. Berthault, F.; Kintz, P.; Mangin, P.; J. Chromatogr. 1996, 685,386

24. Song, D. M.; Zhang, S.; Kohlhof, K.; J. Chromatog. B 1994, 658, 142.

25. Yoshida, M.; Akane, A.; Anal. Chem. 1999, 71, 1918.

26. Fugatami, K.; Narazaki, C.; Kataoka, Y.; Shuto, H.; Oishi, R.; J. Chromatogr. B 1997, 704, 369.

27. Pauwels, A. N.; Schepens P. J. C.; Int. J. Environ. Anal. Chem. 1998, 71, 105.

28. Marques, E. P.; Gil, F.; Proença, P.; Monsanto, P., Oliveira, M. F.; Castanheira, A.; Vieira, D. N.; Forens. Sci. Int. 2000, 110, 145.

29. Stebler, T.; Guentert, T. W.; J. Chromatogr. 1991, 564,330 .

30. Zavitsanos, A. P., MacDonald, C., Bassoo, E.; Goupaul, D.; J. Chromatogr. B 1999, 730, 9.

31. Kimiskidis, V., K.; Kazis, A. D.; Niopas, I.; J. Liq. Chromatogr. Relat. Technol. 1996, 19, 1267.

32. Van Gijn, R.; Havik, E.; Boven, E.; Vermorken, J. B.; ten Bokkel Huinink, W. W.; van Tellingen, O.; Beijnen, H.; J. Pharm. Biomed. Anal. 1995, 14, 165.

33. Henion, J.; Brewer, E.; Rule, G.; Anal. Chem. 1998, 70,650

34. Jemal, M.; Teitz, D.; Ouyang, Z.; Khan, S.; J. Chromatogr. $B$ 1999, 732, 501 .

35. Zhang, N. Y.; Hoffman, K. L.; Li, W. L.; Rossi, D. T.; J. Pharm. Biomed. Anal. 2000, 22, 131.

36. Ramos, L.; Bakhtiar, R.; Tse, F. L. S.; Rapid Commun. Mass Spectrom. 2000, 14, 740.

37. Zweigenbaum, J.; Heinig, K.; Steinborner, S.; Wachs, T.; Henion, J.; Anal. Chem. 1999, 71, 2294.

38. Zweigenbaum, J.; Henion, J.; Anal. Chem. 2000, 72, 2446.

39. Hennion, M. C.; J. Chromatogr. A 1999, 856, 3.

40. Majors, R. E.; LC-CG Supplement 1998, Maio, 8.

41. Lingeman, H.; Hoekstra-Oussoren, S. J. F.; J. Chromatogr. B 1997, 689, 221. 
42. Liebich, H. M.; Di Stefano, C.; Wixforth, A.; Schimid, H. R.; J Chromatogr. A 1997, 763, 193.

43. Mitchell, E. P.; Evans, L.; Schultz, P.; Madsen, R.; Yarbro, J. W.; Gehrke, C. W.; Kuo, K.; J. Chromatogr. 1992, 581, 31

44. Shen, H.; Aspinwall, C. A.; Kennedy, R. T.; J. Chromatogr. B 1997, 689, 265.

45. Rosenfeld, J. M.; Moharir, Y.; Hill, R.; Anal. Chem. 1991, 63, 1536

46. Andersson, L. I.; J. Chromatogr. B 2000, 739, 163.

47. Stevenson, D.; Trends Anal. Chem. 1999, 18, 154

48. Karlsson, L., Owens, P. K.; Lutz, E. S. M.; Andersson, L. I.; Trends Anal. Chem. 1999, 18, 146.

49. Ensing, K.; Boer, T.; Trends Anal. Chem. 1999, 18, 138.

50. Börje, S.; Trends Anal. Chem. 1999, 18, 164.

51. Andersson, L. I.; Paprica A.; Arvidsson, T.; Chromatographia 1997, 46, 57.

52. Martin, P., Wilson, L. D.; Morgan, D. E.; Jones, G. R.; Jones, K.; Anal. Commun. 1997, 34, 45.

53. Sellergren, B.; Anal. Chem. 1994, 66, 1578.

54. Rashid, B. A.; Briggs, R. J.; Hay, J. N.; Stevenson, D.; Anal. Commun. 1997, 34, 303.

55. Wlashe, M.; Horwarth, J.; Kelly, M. T.; O’Kennedy, R.; Smyth, M. R.; J. Pharm. Biomed. Anal. 1997, 16, 319.

56. Unger, K. K., Chromatographia. 1991, 31, 507.

57. Boos, K. S.; Grimm,C. H.; Trends Anal. Chem. 1999 , $175,18$.

58. Hagen, D. F.; Markell, C. G.; Schmitt, G. A.; Anal. Chim. Acta 1990, 286, 157.

59. Wells, D. A.; Lensmeyer, G. L.; Wiebe, D. A.; J. Chromatogr. Sci. 1995, 33, 386.

60. Blevins, D. D.; Hall, D. O.; LC-CG Supplement 1998, Maio, 16.

61. Campíns-Falcó, P.; Herráez-Hernández, R.; SevillanoCabeza, A.; J. Chromatogr. 1993, 619, 177.

62. Seki, T.; Yamaji, K.; Orita, Y.; Moriguchi, S.; Shinoda, A.; J. Chromatogr. A 1996, 730, 139.

63. Hyotylainen, T.; Andersson, T.; Riekkola, M-L.; J. Chromatogr. Sci. 1997, 35, 280.

64. Hyotylainen, R.; Pilvio, R.; Riekkola, M-L., J. High Resol. Chromatogr., 1996, 19, 439.

65. Arthur, C. L.; Pawliszyn, J.; Anal. Chem. 1990, 62, 2145.

66. Valente, A. L. P.; Augusto, F.; Quim. Nova 2000, 23, 523.

67. Lord, H.; Pawliszyn, J.; J. Chromatogr. A 2000, 885, 153.

68. Kumazawa, T.; Seno, H.; Lee., X-P.; Ishii, A.; Suzuki, O.; Sato, K.; Chromatographia 1996, 43, 393.

69. Lee, X-P.; Kumazawa, T.; Sato, K.; Suzuki, O.; Chromatographia 1996, 42, 135.

70. Ishii, A.; Seno, H.; Kumazawa, T.; Watanabe, K.; Hattori, H.; Suzuki, O.; Chromatographia 1996, 43, 331.
71. Lee, X-P.; Kumazawa, T.; Sato, K.; Suzuki, O.; J. Chromatogr. Sci. 1997, 35, 302.

72. Levy, J. M.; $L C$-GC 1999, 17, 14.

73. Liu, H.; Cooper, L. M.; Raynie, D. E.; Pinkston, J. D.; Wehmeyer, K. R.; Anal. Chem. 1992, 64, 802.

74. Liu, H.; Wehmeyer, K. R.; J. Chromatogr. B 1994, 657, 206.

75. Johansen, H. R.; Thorstensen, C.; Greibrokk, T.; Becher, G.; J. High Resol. Chromatogr. 1993, 16, 148.

76. van der Merbel, N. C.; J. Chromatogr. A 1999, 856, 55.

77. Debets, A. J. J.; Kok, W. Th.; Hupe, K. P.; Brinkman, U. A. Th.; Chromatographia 1990, 30, 361.

78. Buscher, B. A. P.; Hofte, A. J. P.; Tjaden, U. R.; van der Greef, J.; J. Chromatogr. A 1997, 777, 51.

79. Buscher, B. A. P.; Tjaden, U. R.; van der Greef, J.; J. Chromatogr. A 1997, 764, 135.

80. Buscher, B. A. P.; Tjaden, U. R.; van der Greef, J.; J. Chromatogr. A 1997, 788, 165.

81. van de Merbel, N. C.; Hageman, J. J.; Brinkman, U. A. Th.; J. Chromatogr. 1993, 634, 1.

82. Ceccato, A.; Toussaint, B.; Chiap, P.; Hubert, P.; Crommen, J.; J. Pharm. Biomed. Anal. 1997, 15, 1365.

83. Johansen, K; Krogh, M.; Rasmussen, K. E.; J. Chromatogr. B 1997, 690, 223.

84. Shintani, H.; J. Chromatogr. Sci. 1996, 34, 92.

85. Chiap, P.; Hubert, Ph; Boulanger, B.; Crommen, J.; Anal. Chim. Acta 1999, 391, 227.

86. Oravcová, J.; Bohs, B.; Lindner,W.; J. Chromatogr. B 1996, 677, 1 .

87. Rossi, D. T.; Wright, D. S.; J. Pharm. Biomed. Anal. 1997, 15, 495.

88. Su, Y.; Hen Y. Y.; Chu, Y. Q.; van der Poll, M. E. C.; Relling, M. V.; J. Chromatogr. B 1999, 732, 459.

89. Bantan, T.; Milacic, R.; Mitrovic, B.; Pihlar, B.; J. Anal. At. Spectrom. 1999, 14, 1743.

90. Koehler, J. A.; Ulbricht, M.; Belfort, G.; Langmuir 1997, $13,4162$.

91. Ma, M. H.; Cantwell, F. F.; Anal. Chem. 1998, 70, 3912.

92. Pedersen-Bjergaard, S.; Rasmussen, K. E.; Anal. Chem. 1999, 71, 2650.

93. Chimuka, L.; Megersa, N.; Norberg, J.; Mathiasson, L.; Jonsson, J. A.; Anal. Chem. 1998, 70, 3906.

94. Jönsson, J. A.; Mathiasson, L.; Trends Anal. Chem. 1999, $18,318$.

95. Jönsson, J. A.; Mathiasson, L.; Trends Anal. Chem. 1999, 18,325 .

96. Trocewicz, J.; Suprynowics, Z.; Markowics, J.; J. Chromatogr. B 1996, 685, 129.

97. Smith, G. A.; Lloyd, T. L.; LC-GC Supplement 1998, Maio, S22. 